\title{
Assessment of a Simplified Model of a Wave Energy Converter in Terms of Hydraulic Mechanical and Electrical Parameters
}

\author{
Miftah Al Karim, Md. Hasib Noor, Mohammad Nasim, Saiful Islam Khan \\ Faculty of Engineering (Electrical and Electronic Engineering department), American International University of Bangladesh, Dhaka, \\ Bangladesh
}

\section{Emai address:}

miftah@aiub.edu (Miftah. A. K.), hasibnoor@aiub.edu (Md. H. Noor), nasim@aiub.edu (M. Nasim), saifkhan@aiub.edu (S. I. Khan)

\section{To cite this article:}

Miftah Al Karim, Md. Hasib Noor, Mohammad Nasim, Saiful Islam Khan. Assessment of a Simplified Model of a Wave Energy Converter in Terms of Hydraulic Mechanical and Electrical Parameters. International Journal of Energy and Power Engineering.

Vol. 4, No. 2, 2015, pp. 94-102. doi: 10.11648/j.ijepe.20150402.20

\begin{abstract}
Developing different models of ocean energy converters have been getting much attention in recent times, due to a globally coherent consciousness towards different types of renewable energy sources. Development of any novel concept is preceded by acute understanding of previous yet similar ideas, which in fact is preceded by understanding of simplified observations of those ideas. This paper discusses the principle operation and modeling of a highly portable ocean energy generator called 'Pelamis Wave Energy Converter' from a simplistic point of view. The purpose of this paper is to make its readers understand the inherent mathematics and mechanics of a 'Pelamis wave energy converter' and preparing a simplified model using 'Simulink' software. Along with the modeling this paper also evaluates the output power in terms of different parameters such as hydraulic fluids, levels of input torque, variable wave pressures on the surface, capacitive loads etc.
\end{abstract}

Keywords: Wave Energy Converter, Modeling, Hydraulic System, Electro-Mechanical System, Pelamis, Renewable Energy

\section{Introduction}

Ocean waves can be considered as the product of interaction between wind flow and ocean surface. As wind flows due to the imbalance of heat distribution on the surface of the earth, in a broad sense thus waves can be considered as an indirect product of solar energy [1] [2]. Water has higher density than wind, which contributes to the characteristics of a sea wave of having the highest energy density among all the popular renewable sources [3] [4]. The global potential of wave energy from theories has been anticipated to be 32000 $\mathrm{TWh} /$ year, which is almost double of the electricity supply took place throughout the world in 2008 [3]. Assuming that the wave energy converters have $40 \%$ efficiency and these are installed near the coastlines with a mean energy of $30 \mathrm{KW} / \mathrm{m}$, global technical potential of wave power is around $500 \mathrm{GW}$ [3]. Below a table is provided which reflects the regional theoretical potential of wave energy [3] [11].

Different reviews have taken place on ocean energy generation techniques and studies show that so far, out of many prototypes of wave energy converters few have been tested in large scale [5] [12]. The potentiality therefore is immense in terms of studying different methods as well as studying the use case scenarios of a particular method [12].

Table 1. Regional theoretical potential of wave energy [6]

\begin{tabular}{ll}
\hline Region & Wave Energy TWh/year \\
\hline Western and Northern Europe & $2,800(10.1)$ \\
Mediterranean Sea and Atlantic Archipelagos & $1,300(4.7)$ \\
(Azores, Cape Verde, Canaries) & $4,000(14.4)$ \\
North America and Greenland & $1,500(5.4)$ \\
Central America & $4,600(16.6)$ \\
South America & $3,500(12.6)$ \\
Africa & $6,200(22.3)$ \\
Asia & $5,600(20.2)$ \\
Australia, New Zealand and Pacific Islands & $29,500(106.2)$ \\
Total & \\
\hline
\end{tabular}

\section{Different Types of Wave Energy Converters}

Presently different methods thus models of wave energy converters are available. In spite of having such differences these converters can be categorized into three major types; 
'Attenuator', 'Point absorber', 'Terminator' [5] [12] [13]. Attenuator types lie in the parallel position to the wave direction. Point absorbers are floating devices that can move upwards and downwards based on the wave heights. Terminator types lie in perpendicular position with the wave direction [12] [13].

\section{Significant Examples}

Multiple models of ocean energy converters have been developed by different companies in the past decades [13] [14]. The successful operation and ongoing development of different models from a technology readiness as well as survivability point of view have been carried out by reference-[13]. The criteria set to check such progress is a questionnaire as following;

1. "Was the device team responsive to data requests making an initial assessment possible?"

2. "Is the device likely to be ready for demonstration by 2006?"

3. "Is survivability addressed satisfactorily in the response?"

After exhaustive screening process reference-[13] has reached to a verdict identifying different issues from their request for information obtained from ten models. The list is shown below.

Table 2. Initial Screening of Responses [13]

\begin{tabular}{lllll}
\hline Company & Device Name & Technology Readiness & Survivability & Company \\
\hline Aqua Energy & Aqua BuOY & Yes & Yes & Aqua Energy \\
Energetech & OWC & Yes & Yes & Energetech \\
Independent Natural Resources & Wave Dog & Yes & Yes & Independent Natural Resources \\
Ocean Power Delivery & Pelamis & Yes & Yes & Ocean Power Delivery \\
Ocenergy & WavePump & No & Yes & Ocenergy \\
OreCON & Offshore OWC & Yes & Yes & OreCON \\
Teamwork & Wave Swing & Yes & Yes & Teamwork \\
Waveberg & Waveberg & No & Yes & Waveberg \\
WaveBob Ltd. & Wavebob & Yes & Yes & WaveBob Ltd. \\
\hline
\end{tabular}

The overall screening carried out in [13] is based on 'data sourcing methodology: quality and depth of data', '1,500 MWh Pilot Plant and 300,000 MWh Commercial Plant Rough Sizing', and 'cost estimation'. The summary of the results reflects that the model 'Pelamis' of ocean power delivery or otherwise widely known as sea-snake (model P1) is more stable, almost fully developed and ready for large scale operations [13] [18]. It has high assurance of performing expectedly and project risks have been significantly reduced [16] [18]. [12] is a significant referee to consider 'Pelamis wave energy converter' for further analysis.

\section{Brief Overview on Pelamis Energy Converter}

The Pelamis wave energy converter (model P1) is a semi submerged articulated construction. It can be of $180 \mathrm{~m}$ long with an outer diameter of 3.5 meters. It weights around 1300 tons [20]. There are around five compartments connecting four converting modules [12] [16] [18]. Each of the machines is rated $750 \mathrm{KW}$. Depending on different parameters such as installation site, wave characteristics etc. the Pelamis can produce on an average around $25-40 \%$ of its rated capacity [16] [17] [18]. Up to the present date Pelamis has produced six full scale machines including two of the latest ' $P 2$ ' design [18]. Since its inception 'Aguçadoura project' has been one of the successful projects for Pelamis [17] [18]. This project has achieved several milestones; built and operated world's first wave-farm, simulation results matched the practical data, remote control and monitoring, establishment of safe and cost effective maintenance base, supply chain management has been enhanced and developed etc. and more.

If appropriately installed Pelamis has the potentiality to become one of the most environment friendly renewable energy devices. It has multiple protection levels to protect the sea in an unlikely event if hydraulic fuel leaks. Besides it contains small quantities of transmission fluid. The possibility of marine mammals and fish to temporarily or permanently lose their hearing sensitivity is insignificant [18] [19].

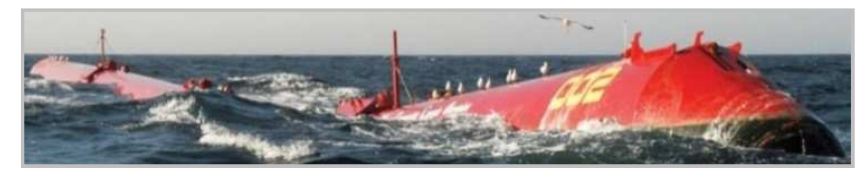

Figure 1. Pelamis wave energy converter (http://www.pelamiswave.com/pelamis-technology, 14th January 2015)

\subsection{The Technology}

Body of the Pelamis converter is made up of five tube-like segments. The tubes are linked to each other by joints that accommodate flexing in multiple directions. The structure is semi submerged and it is set in parallel to the direction of the wave. When wave passes through the front to tail of the machine, the tubes move upward or downward direction due to the wave motion. This motion is then mechanically converted to unidirectional kinetic energy by a hydraulic power take off system. The hydraulic system is stored inside the joints in between two tubes. The produced kinetic energy 
can be used to rotate a generator. Thus electricity is produced from wave motion in a Pelamis wave energy converter [18].

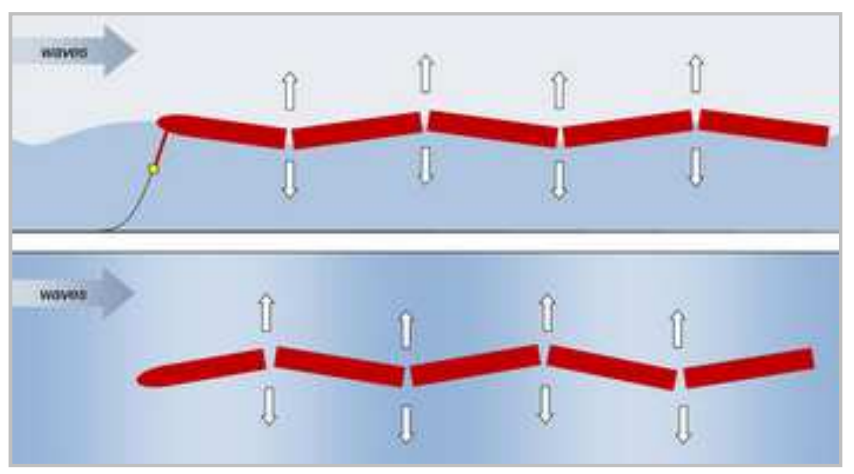

Figure 2. Motion of Pelamis tubes with waves

(http://www.pelamiswave.com/pelamis-technology, 14th January 2015)

The hydraulic cylinders near the joints harness the wave motion and pump a fluid into a pressurized accumulator that can produce up to $2.5 \times 10^{7}$ Pascal of pressure. The pressurized accumulator is used to ensure smooth power generation. During storms hydraulic systems introduce higher resistivity against the wave motion thus protecting both the machines as well as generators from producing over current [18] [20].

\subsection{Energy Absorption Principle}

Pelamis works on the principles of 'line absorber technology' [13] [20]. In a line absorber principle the wave energy is absorbed by an elongated structure extended in parallel with the direction of an approaching wave. This method facilitates maximum energy capture for a given volume in spite of not having any fixed physical reference constructed on the sea bed. This is a competitive advantage offered by pelamis. The analogy of such an advantage is to compare the advantage of using lift force over drag force in modern wind turbines. It often confuses developers that the wave energy converters only harness the energy from the wave just passing underneath the surface. Rather wave energy conversion critically depends on the entire wave field. That is why the energy obtained from waves can be expressed as its capture width. The capture width on the other hand mathematically is a direct function of the incoming wavelength ' $\lambda$ '. Thus in general the capacity of energy absorption of a machine is given as a fraction of the wavelength of the surrounding wave area [20]. Another method to understand power flux in a wave is to study the wave amplitudes [21]. Below a comparative data of order estimates of power flux per unit length of wave front is given in a tabular form.

Table 3. Order estimate of power flux per unit length of wave-front [21]

\begin{tabular}{ll}
\hline amplitude $(\mathbf{m})$ & power flux $\left(\mathrm{kWm}^{-1}\right)$ \\
\hline 0.5 & 10 \\
1 & 40 \\
2 & 60 \\
\hline
\end{tabular}

\subsection{Background Studies on Power Capture}

From a general aspect it is considered that the body induced disturbances or impacts on wave motion as well as height are negligible. Such an idea allows implying that linearization techniques can be applied to understand the interactions between water wave and a structure. Under this assumptions water is described by velocity potential $\Phi$ or by time-independent complex amplitude of the velocity potential $\phi$ [13] [20] [21]. $\phi$ can be expressed as;

$$
\phi=A_{0} \varphi_{0}+A_{0} \varphi_{d}+A_{z} \varphi_{z}
$$

Here $A_{0}=$ complex amplitude of the incident wave, $\varphi_{0}$ and $\varphi_{d}$ are the velocity potentials.

Furthermore $\phi$ it can be expressed as;

$$
\Phi=\mathfrak{R}\left\{\phi e^{-i \omega t}\right\}
$$

Here ' $\omega$ ' is angular frequency

Velocity potential satisfies the Laplace equation,

$$
\nabla^{2} \phi=0,-h<z<0
$$

Here $z$ belongs to a three dimensional plane and z-axis directs towards vertically upward. The surface plane of an undisturbed water body is considered at $z=0$ and surface bottom at a height of $z=-h$. After applying linear approximation considering the waves are small and atmospheric pressure is constant at $z=0$ the boundary conditions at sea bed are as following;

$$
\begin{gathered}
\frac{\partial \phi}{\partial z}=0, z=-h \\
-\omega^{2} \phi+g \frac{\partial \phi}{\partial z}=0, z=0
\end{gathered}
$$

Here ' $\mathrm{g}$ ' is gravitational acceleration. The boundary condition of the wet surface of 'Pelamis' wave energy converter can be obtained through the following equation;

$$
n \cdot \nabla \phi=-\mathrm{i} \omega n_{z} A_{z}
$$

$n_{z}$ is the component of ' $\mathrm{n}$ ' at the direction of Cartesian coordinate basis $z . A_{z}$ is the complex amplitude of the oscillatory motion of the floating body around the mean position of the body. Once the boundary conditions for oscillatory heaving movement are set, time varying averaged power ' $\mathrm{P}$ ' which is the power transmitted from fluid to the body of 'Pelamis' can be obtained. If the boundary condition of the wet surface of 'Pelamis' wave energy converter is $S_{B}$ then integration of the time average of the pressure ' $p$ ' multiplied by the fluid velocity $\frac{\partial \Phi}{\partial n}$ over $\mathrm{S}_{\mathrm{B}}$ can give the average power ' $\mathrm{P}$ '.

$$
P=\iint_{S_{B}}\left(1 / T \int_{0}^{T} p \frac{\partial \Phi}{\partial n} d t\right) d S
$$

Here $\mathrm{T}=$ the period of oscillation, $\mathrm{T}=\frac{2 \pi}{\omega}$. Under the boundary condition $\mathrm{S}_{\mathrm{B}}$ if ' $\mathrm{P}$ ' is positive then the body is absorbing energy from the fluid and if ' $\mathrm{P}$ ' is negative then the body is exerting energy to the fluid. With the help of 
linearized form of Bernoulli equation the pressure filed is presented as follows;

$$
\frac{\partial \Phi}{\partial t}+g z+\frac{p}{\rho}=\frac{p_{0}}{\rho}
$$

Here $p_{0}$ is the pressure at $z=0$ and $\rho$ is the fluid density. ' $\rho$ ' is considered constant throughout the calculation period and the changes in density due to external influences such as temperature etc. is ignored. Now substituting ' $\Phi$ ' from equation-1, ' $\rho$ ' from equation-7 into the equation- 6 it can be obtained that;

$$
1 / T \int_{0}^{T} p \frac{\partial \Phi}{\partial n} d t=\frac{i \omega p}{4}\left(\phi \frac{\partial \bar{\phi}}{\partial n}-\bar{\phi} \frac{\partial \phi}{\partial n}\right)
$$

Here ' $\bar{\phi}$ ' is the complex conjugate of ' $\phi$ '. After substituting equation- 8 into equation- 6 it is observed that;

$$
P=\frac{i \omega p}{4} \iint_{S_{B}}\left(\phi \frac{\partial \bar{\phi}}{\partial n}-\bar{\phi} \frac{\partial \phi}{\partial n}\right) d S
$$

If the homogeneous boundary conditions obtained from equation-3 and equation-4, are applied as well as green's second identity to the equation-9 it can further be stretched towards a far-field control surface that;

$$
\iint_{S_{B}}\left(\phi \frac{\partial \bar{\phi}}{\partial n}-\bar{\phi} \frac{\partial \phi}{\partial n}\right) d S+\iint_{S_{C}}\left(\phi \frac{\partial \bar{\phi}}{\partial n}-\bar{\phi} \frac{\partial \phi}{\partial n}\right) d S=0
$$

Here $S_{C}$ is the control surface of the cylindrical body. So with the advent of $S_{C}$ the average power becomes;

$$
P=-\frac{i \omega p}{4} \iint_{S_{C}}\left(\phi \frac{\partial \bar{\phi}}{\partial n}-\bar{\phi} \frac{\partial \phi}{\partial n}\right) d S
$$

\section{Preparation of the Simplified Model}

This section discusses the preparation stage of the simplified model of 'Pelamis wave energy converter' otherwise known as the sea snake (model P1). To model the design a block diagram environment for multi-disciplinary simulation tasks called 'Simulink' has been used [23] [24].

To prepare a simplified model, initially it is considered that the ocean waves can be represented as a sine wave. The amplitude of the sine wave represents height of the incident wave and the frequency represents the wave motion [22]. Figure- 3 and figure- 4 show how the input waves have been compared to constant amplitude and constant frequency sinusoidal signal. The absolute value of the rate of change of the magnitudes in this signal has also been considered constant.

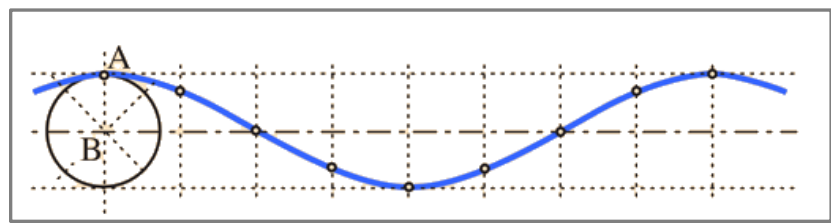

Figure 3. Ocean wave represented as sinusoidal signal [22] (as of 14th January 2015)

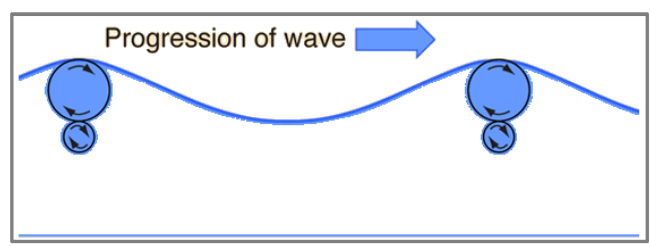

Figure 4. Progression of wave [22] (as of 14th January 2015)

The pelamis tubes move upward and downward along with this sinusoidal signal and the frequency of movement is equal to the frequency of the signal. In the following section a model of only one generating unit in between two tubes wll be addressed. It is considered that the frontal tube is responsible to move the turbine by pushing the fluid through an actuator and the rear tube ensures the fluid moves backward to the initial position. So power will be produced only for the upward dispacement of the frontal tube. The overall modeling is carried out using 'Simulink'. At the time when the tube moves upward direction it initiates a pressure on a two position valve actuator threshhold set allows to control the position of the directional valves. The output of this valve-block is a physical signal that can be interpretted either as a mechanical translation or rotational push-pin motion. The push-pin actuates when the input signal touches $50 \%$ mark of the nominal value. Here the nominal signal is a block parameter that is mentioned in table-4. The push-pin motion is divided into three parts; delay (t1), constant acceleration motion ( $\mathrm{t} 2)$ and the motion at fixed velocity ( $\mathrm{t} 3)$. In this experiment after actuation the entire motion is considered as a constant velocity motion $(\mathrm{t} 1+\mathrm{t} 2+\mathrm{t} 3)$. The stroke value is represented by $\mathrm{X}_{\mathrm{STR}}$ [24].

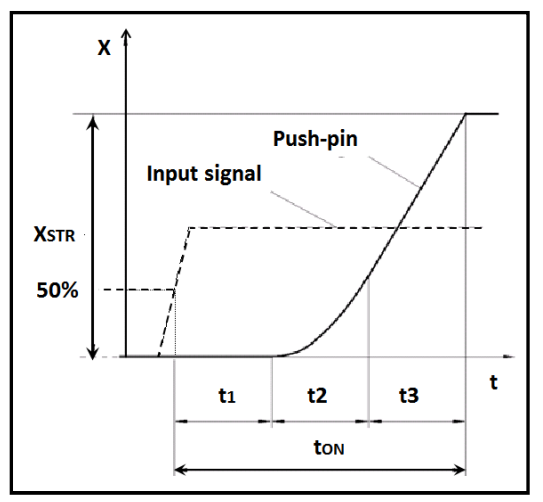

Figure 5. Theoretical motion of the push-pin [24]

The sinusoidal signal used do not provide any information about the pressure it is putting on the pelamis surface. To portray a pressure based valve conrtrollinga hydraulic pressure source has been used source of hydraulic energy which can maintain a constant pressure regardless the consumption by the system. The ports ' $\mathrm{T}$ ' and ' $\mathrm{P}$ ' represents to the hydraulic inlet and outlet ports. A constant value can be assigned to its physical signal input port that holds the information about how much pressure the ocean waves are putting on the hydraulic valves. The magnitude of pressure controls the overall output power 
obtained from the generator. Outout of the hydraulic pressure source is then carried out towards a hydraulic continuous

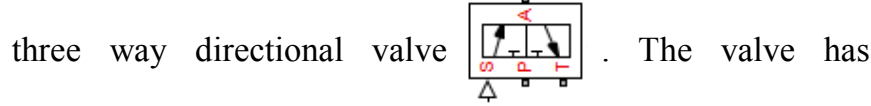
connections in it. One is inlet port (P) which can be associated to the output of the hydraulic pressure source, one return port $(\mathrm{T})$ and one actuator port $(\mathrm{A})$. There is a physical signal port $(\mathrm{S})$ that controls the spool position. In this experiment the spool position is manipulated by two-position valve actuator and the parameters set in it. The inlet port is connected to the output of the hydraulic pressure source. The return ports of both the pressure source and valve is connected to a hydraulic reference frame $L \downarrow$ that represents a connection to the atmospheric pressure. The directional valve is goverened by a set of equations [24];

$$
\begin{aligned}
& h_{P A}=h_{P A 0}+x \\
& h_{A T}=h_{A T 0}-x
\end{aligned}
$$

$\mathrm{h}_{\mathrm{PA}}=$ Orifice opening for the orifice_PA block; $\mathrm{h}_{\mathrm{PA} 0}=$ Initial opening for the orifice_PA block; $\mathrm{h}_{\mathrm{AT}}=$ Orifice opening for the orifice_AT block; $\mathrm{h}_{\mathrm{AT} 0}=$ Initial opening for the orifice_AT block; $\mathrm{x}=$ Control member displacement from initial position. The actuator port (A) then is connected to the hydraulic conserving port (A) associated with the cylinder inlet in a single acting hydraulic cylinder purpose of using the single acting hydraulic cylinder is to convert the hydraulic energy to mechanical energy. The rod displacement inside the cylinder can be calculated by the following equation [24];

$$
X_{p s t}=X_{0}+X_{P}
$$

Here, $X_{p s t}$ is the rod displacement, $X_{0}$ is initial distance between the piston and the cap and $X_{P}$ is the rod displacement comparing to it's initial position. The parameters that define characteristics of the cylinder, valve and actuator can be observed and/or manipulated by the data provided in table-4.

Table 4. Initially chosen parameters of different hydraulic equipment

\begin{tabular}{lcl}
\hline \multicolumn{3}{l}{ Parameters of the two position valve actuator } \\
\hline Parameter name & values & units \\
Push-pin stroke & 0.01 & meter \\
Switching-on time & 0.1 & second \\
Switching-off time & 0.1 & second \\
Nominal signal value & 20 & \\
Parameters of the directional valve (by maximum area and opening) \\
Valve passage maximum area & $1 \mathrm{e}-4$ & Square meter \\
Flow discharge coefficient & 0.7 & \\
Orifice P-A initial opening & 0 & meter \\
Orifice A-T initial opening & .08 & meter \\
Critical Reynolds number & 12 & \\
Leakage area & $1 \mathrm{e}-6$ & Square meter \\
Parameters of the single acting hydraulic cylinder & \\
Piston area & 0.002 & Square meter \\
Piston stroke & 0.25 & meter \\
Initial distance between piston and cap & 0.05 & meter \\
Dead volume & $1 \mathrm{e}-6$ & Cubic meter \\
Chamber initial pressure & 0 & Pascal \\
\hline
\end{tabular}

\begin{tabular}{lcl}
\hline \multicolumn{3}{l}{ Parameters of the two position valve actuator } \\
\hline Specific heat ratio & 1.4 & \\
Contact stiffness & $1 \mathrm{e} 7$ & $\mathrm{~N} / \mathrm{m}$ \\
Contact damping & 250 & $\mathrm{~N} /(\mathrm{m} / \mathrm{s})$ \\
\hline
\end{tabular}

One of the importances of the hydraulic cylinder is mechanical translational conserving port that associates with the cylinder clamping structure. Mechanical translational conserving port associates with the cylinder rod and it is connected to mechanical transitional mass also to mechanical transitional references through mechanical transitional spring and mechanical transitional damper. To ensure operation of the hydraulic system a hydraulic fluid block has also been added that can comprehend system characteristics based on different types of fluids available inside the hydraulic system [23] [24]. The physical signal output from the hydraulic cylinder refers to the current position of the piston in the form of its stroke [24]. The piston resides inside the cylindrical chamber. The stroke of the piston plays a key role here to mimic the mechanical input force to the electricity generating module. As the shifting of piston position is considered a constant motion the input mechanical power has two values towards the generating unit. The values initially have been set 1 per unit for positive strokes and 0.2 per unit for zero strokes or retracting back of the piston to its initial position. These two incidents of the mechanical input are controlled by a switch block considered that the switch and the constant mechanical input values of the simulation model reduce the use of an additional accumulator and hydraulic motor to maintain a steady fluid flow that ensures steady mechanical input.

There are different generator modules in 'Simulink'. From [20] it is known that 'Pelamis' wave energy converters use induction generators to produce power that lead the modeling process to select an induction generator. The generating unit has been constructed with multiple blocks, a three phase induction generator, a three phase parallel RLC-load, a three phase transmission line and a series RLC-load. Figure-5 shows the parameters set for the induction generator.

The induction generator model is a current source that's why a parallel RLC-load with a very low power rating has been connected to it. The parameters have been manipulated

\begin{tabular}{|c|}
\hline Nominal power, voltage (line-line), and frequency $[\mathrm{Pn}(\mathrm{VA}), \mathrm{Vn}(\mathrm{Vrms}), \mathrm{fn}(\mathrm{Hz})]$ \\
\hline$[1000 \mathrm{e} 312 \mathrm{e} 360]$ \\
\hline Stator resistance and inductance $[\mathrm{Rs}, \mathrm{Lls}](\mathrm{pu})$ : \\
\hline$\left[\begin{array}{lll}0.01965 & 0.0397\end{array}\right]$ \\
\hline Rotor resistance and inductance $\left[\mathrm{Rr}^{\prime}, \mathrm{Ll} \mathrm{r}^{\prime}\right](\mathrm{pu})$ : \\
\hline$\left[\begin{array}{lll}0.01909 & 0.0397\end{array}\right]$ \\
\hline Mutual inductance Lm (pu): \\
\hline 1.354 \\
\hline Inertia constant, friction factor, pole pairs $[H(s) F(p u) p()]$ : \\
\hline$\left[\begin{array}{lll}0.09526 & 0.05479 & 2\end{array}\right]$ \\
\hline Initial conditions \\
\hline$\left[\begin{array}{lll}0,0 & 1,1,1 & 0,120,240\end{array}\right]$ \\
\hline
\end{tabular}
to reflect on, around $60 \%$ machine efficiency. Below the overall is model is shown in figure-7.

Figure 6. Parameters of the induction generator 


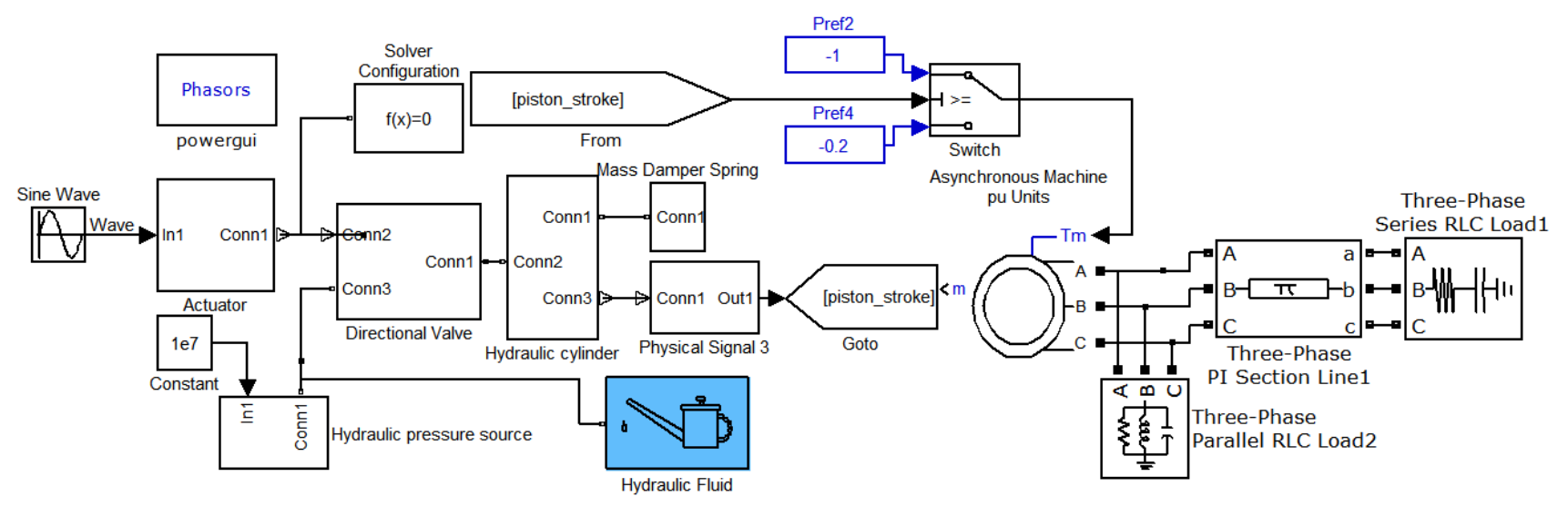

Figure 7. The overall model of 'Pelamis' wave energy converter

\section{Result Analysis}

Once the model has been prepared it was tested by calibrating different parameters that represent key characteristics of the hydraulic, mechanical and electrical models. The ocean waves have been considered of having a fixed peak to peak height of ' 4 ' meters and a frequency of ' $0.25 \mathrm{~s}^{-1}$. The actuator is turned on by the positive cycle of the ocean wave capturing power only from the upward direction of the waves.

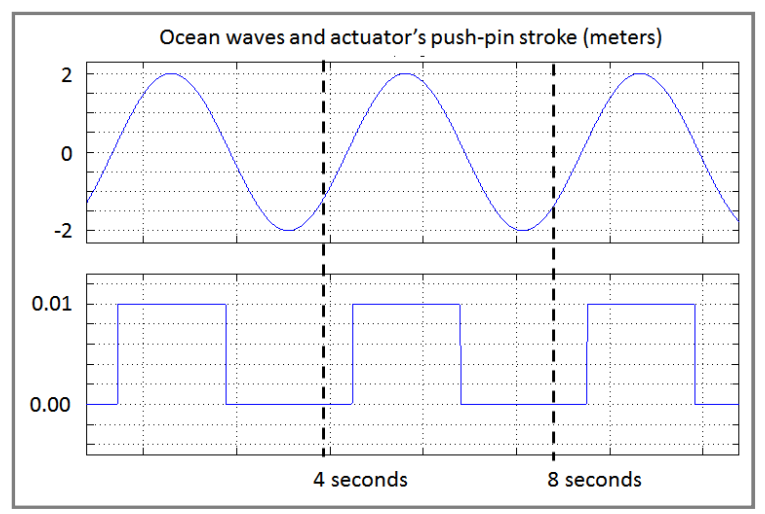

Figure 8. Relative push-pin stroke of the actuator

The stroke of the piston inside the hydraulic cylinder is also given which is synchronous with the push-pin stroke of the valve actuator.

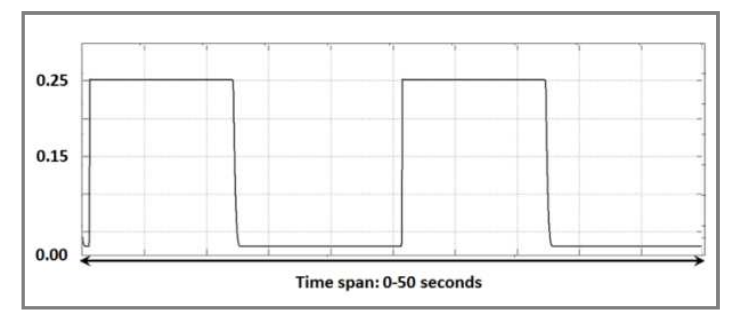

Figure 9. Stroke of the piston

The piston stroke is used in this experiment to instigate the mechanical power input as form of torques. The value '-1 per unit' represents maximum torque during the positive half cycle of the waves and the value referring to ' -0.2 per unit' represents the mechanical input during the retraction period of the piston. Here by term 'retraction torque' or 'retracting torque' it is meant the remaining torque in the system due to the machine inertia while hydraulic piston is moving backward. The input values are also synchronous with the push-pin stroke of the valve actuator.

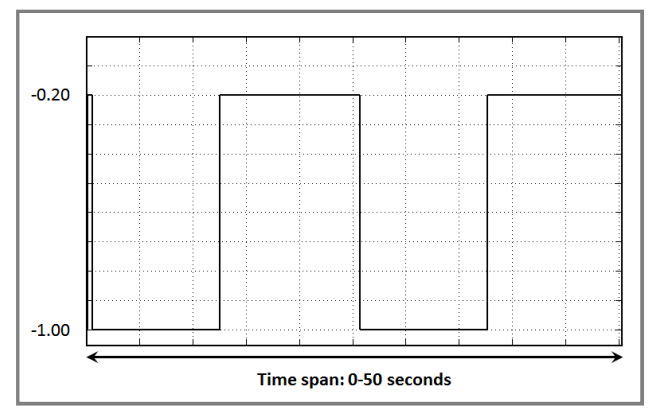

Figure 10. Input torque in per unit (negative values represents generator)

The overall power output from the induction generator highly depends on several factors, for example; retracting input torque, series capacitance, pressure of the wave etc. Relation between the output power and the average power is shown below;

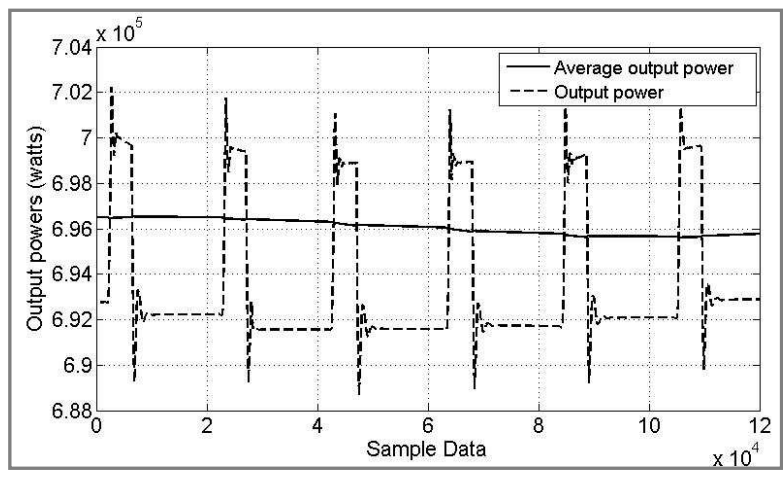

Figure 11. Moving average output power (watts)

To understand the characteristics of this model the values 
mentioned above have been varied and the output power is recorded. The comparisons are shown below with the help of multiple comparative plots. The output power is presented in the form of moving average values.

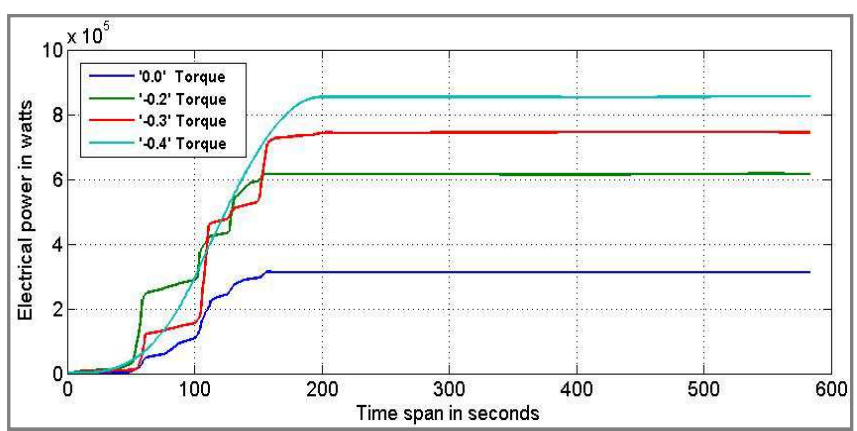

Figure 12. Output power variation (watts) with the variation of retraction torque (P.U.)

The figure-10 shown above is the variation of output power (average) in terms of different retracting torques while wave pressure $\left[1 \times 10^{7} \mathrm{~Pa}\right]$, series capacitance $[0.15 \mathrm{kVar}]$ and fluid type [Skydrol-LD4] are considered unchanged. This method of varying one while keeping others constant is followed for all the comparisons presented next.

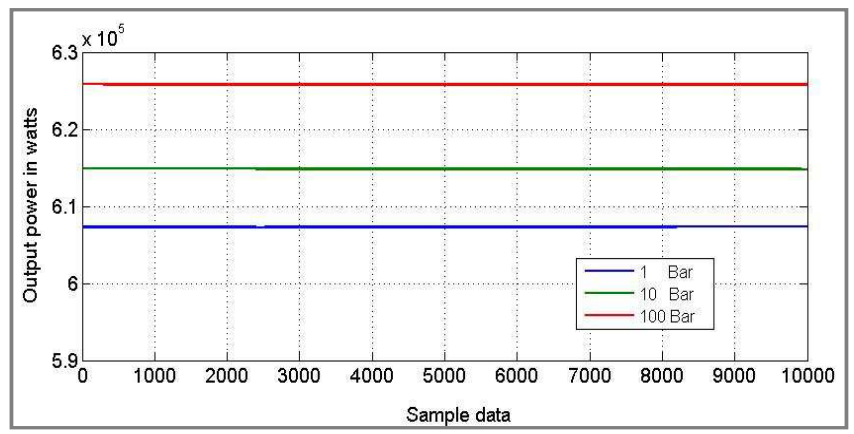

Figure 13. Steady output power (average in watts) with the variation of pressure (Bar) at a constant retracting torque of ' $-0.2 P U$ '

'Simulink' offers different types of hydraulic fluids that vary in density and viscosity. Using each type of fluid has its own merits and demerits if used in a specialized system [24].

Table 5. Different types of hydraulic fluid

\begin{tabular}{lll}
\hline Fluid type & Density $\left(\mathbf{k g} / \mathbf{m}^{3}\right)$ & Viscosity $(\mathbf{c S t})$ \\
\hline Skydrol-LD4 & 977.499 & 10.87 \\
Water & 992.562 & 00.65 \\
ATF Dexron-III & 865.400 & 36.13 \\
Oil-30W & 850.000 & 84.24 \\
Fluid MIL-f-5606 & 847.400 & 12.15 \\
ISO VG 32 & 857.200 & 31.81 \\
\hline
\end{tabular}

Below a comparative study has been shown how output power may vary based on different types of fluid present in the system. Wave pressure has been kept constant at $1 \times 10^{7}$ $\mathrm{Pa}$.

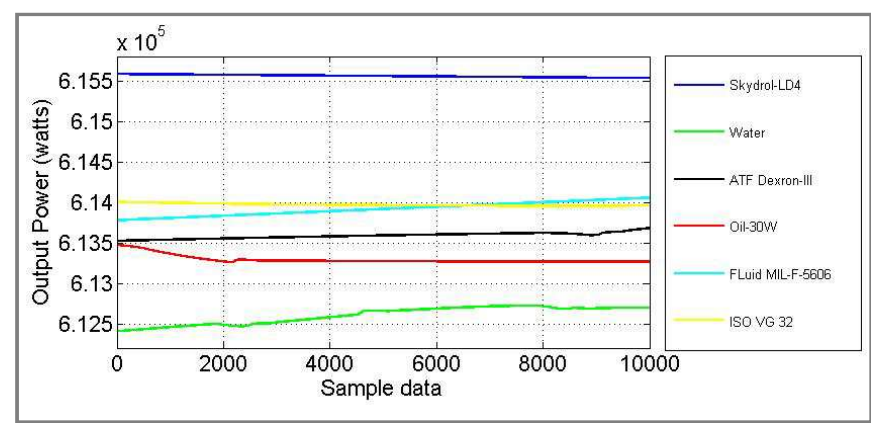

Figure 14. Steady output power (average in watts) with the variation of fluid type

The impact of the variable series capacitance is quite erratic. Thus, a further investigation can be suggested. Below one comparison is shown keeping wave pressure, torque and fluid type constant.

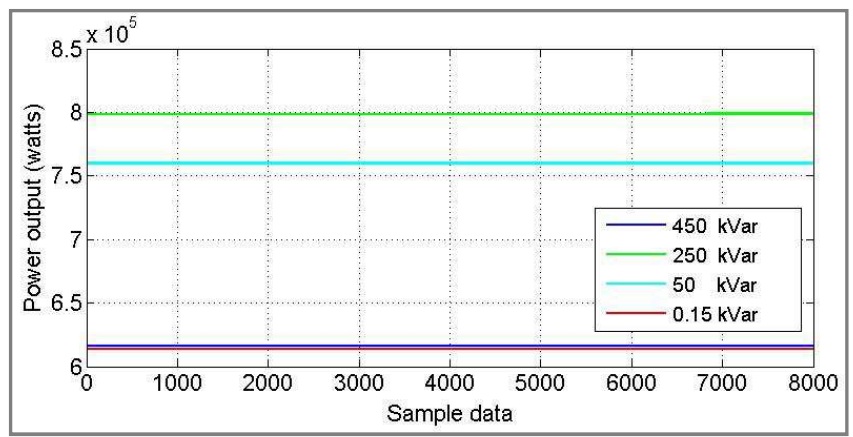

Figure 15. Effect of different series capacitance on steady output power (average in watts)

The model shows promise and it can be used to assess its application in case specific scenarios for example coastal electrification in Bangladesh. Bangladesh has a vast coastal region with average wave heights between 2 meters to 5 meters. Besides, its wind resource is lower comparing to many nations those frequently generate wind power. The cities, most importantly the capital consumes majority of the energy produced in Bangladesh. Along with around 10\% energy losses countrywide the coastal areas of the nation therefore get apparently lower attention on overall distribution of energy [25] [26] [27]. 'Pelamis wave energy converters' can be a solution towards both the efficient coastal electrification as well as minimizing transmission losses by emphasizing more on distributed generation technologies [25].

\section{Concluding Remarks}

With the present progresses of 'Pelamis wave energy converter' it can be expected that the sea snake model has the potentiality to become one of the most successful renewable energy sources in coming days. The portability of the device allows it to be more flexible to put it into different positions of the ocean with different water depths. In this paper it is observed that the performance of the simulated model has referred towards some steady results. Further calibration 
might provide an optimized output depending on specific requirements or load scenarios. However this paper suggests that apart from the simulations carried out many other issues need to be addressed, such as; variability of waves thus pressures, protection schemes against rough weather, modeling newer versions for better efficiency, power transmission etc. Based on the performance analyses and the characteristics of the simulated model it can be considered that it portrays the subject wave energy converter properly at simplified yet quite an effective level.

\section{References}

[1] Taylor, J. Ocean wave energy: current status and future perspectives, 2008 (Springer, Berlin, Germany).

[2] By Paul A. Lynn, Electricity from Wave and Tide: An Introduction to Marine Energy, 2014 (wiley).

[3] Lewis, A., S. Estefen, J. Huckerby, W. Musial, T. Pontes, J. Torres-Martinez, 2011: Ocean Energy. In IPCC Special Report on Renewable Energy Sources and Climate Change Mitigation [O. Edenhofer, R. Pichs-Madruga, Y. Sokona, K. Seyboth, P. Matschoss, S. Kadner, T. Zwickel, P. Eickemeier, G. Hansen, S. Schlomer, C. von Stechow (eds)], Cambridge University Press, Cambridge, United Kingdom and New York, NY, USA.

[4] H. Sarlak, M. S. Seif, M. Abbaspour, S. Abshenas, "Towards Renewable Energy Development, A Model-Study in Ocean Electricity Generation," 24 ${ }^{\text {th }}$ International Power System Conference, [online]. Available: https://www.google.com/url?sa=t\&rct=j\&q=\&esrc=s\&source $=$ web $\& \mathrm{~cd}=1 \& \mathrm{cad}=$ rja \&uact $=8 \&$ ved $=0 \mathrm{CB} 8 \mathrm{QFjAA} \&$ url $=$ http $\% 3 \mathrm{~A} \% 2 \mathrm{~F} \% 2 \mathrm{Fw} w$ w.inore.org\%2Fdownload\%2F 21984 proce edings_international_power_systems_conferene.pdf $\% 2 \mathrm{~F} \& \mathrm{ei}=$

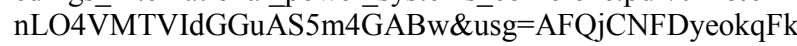
fxVRqoGxxWhG_iOaAcQ\&bvm=bv.83829542,d.c2E [last visited; 16th January 2015] .

[5] BDrew, A R Plummer, andMN Sahinkaya, "A review of wave energy converter technology"Available: http://abs5.me.washington.edu/pub/tidal_wave/a_rewiew_of_WEC_tec h.pdf [last visited; 16th January 2015]. DOI: 10.1243/09576509JPE782.

[6] Gunnar Mørk, Stephen Barstow, AlinaKabuth, M. Teresa Pontes, "ASSESSING THE GLOBAL WAVE ENERGY POTENTIAL". Proceedings of OMAE2010 29th International Conference on Ocean, Offshore Mechanics and Arctic Engineering, June 6-11, 2010, Shanghai, China.

[7] Marthe Kristine TautraHoen, "Modeling and Control of Wave Energy Converters", Doctoral theses at NTNU, 2010, Available: http://www.divaportal.org/smash/get/diva2:403616/FULLTEXT01.pdf [last visited; 16th January 2015].

[8] JosebaLasa, Juan Carlos Antolin, Carlos Angulo, PatxiEstensoro, Maider Santos and Pierpaolo Ricci, "Design, Construction and Testing of a Hydraulic Power Take-Off for Wave Energy Converters", energies ISSN 1996-1073, 2009. Available: www.mdpi.com/journal/energies [last visited; 16th January 2015].

[9] The Pelamis Wave Energy Converter, Available: www.oceanpd.com [2 $2^{\text {nd }}$ December, 2014].
[10] Max Carcas, Business Development Director, "The Pelamis Wave Energy ConverterA phased array of heave + surge point absorbers", www.oceanpd.com [ $2^{\text {nd }}$ December, 2014].

[11] B. Bates, Z. W. Kundzewicz, S. Wu, and J. Palutikof. "Climate change and water. Technical report", Intergovernmental Panel on Climate Change, IPCC, 2008.

[12] MirkoPrevisic, Roger Bedard and George Hagerman, E2I EPRI Assessment Offshore Wave Energy Conversion Devices, E2I EPRI WP - 004 - US - Rev 1, June 16, 2004.

[13] Paul Stansell, David J. Pizer, "arXiv:1112.3494 [physics.fludyn]," Maximum wave-power absorption by attenuating line absorbers under volume constraints, Available: http://arxiv.org/abs/1112.3494v6 [last revised 1 Dec 2012 (this version, v6)].

[14] HMRC, Hydraulic and marine research center, "A Cautiously Optimistic Review of the Technical Status of Wave Energy Technology", http://www.waveplam.eu/files/downloads/SoA.pdf, Available: December 2015].

[15] J. Falnes, Department of Physics, NTNU, N-7034 Trondheim, Norway"PRINCIPLES FOR CAPTURE OF ENERGY FROM OCEAN WAVES PHASE CONTROL AND OPTIMUM OSCILLATION", Available: http://folk.ntnu.no/falnes/web arkiv/InstFysikk/phcontrl.pdf [last visited; 16th January 2015].

[16] Ivan Krishna Compiler, "Ocean-Based Renewable Energy Technologies, SOPAC Miscellaneous Report 701", First Edition October 2009, Available: http://ict.sopac.org/VirLib/MR0701.pdf [last visited; 16th January 2015].

[17] Pelamis wave energy converter technologies, http://www.pelamiswave.com/pelamis-technology, [last visited; 16th January 2015].

[18] Pelamis official webpage, http://www.pelamiswave.com, [last visited; 16th January 2015].

[19] John C. Weiss, Brent B. Boehlert, and Jennifer R. Baxter, "Fiscal Cost-Benefit Analysis to Support the Rulemaking Process for 30 CFR 285 Governing Alternative Energy Production and Alternate Uses of Existing Facilities on the Outer Continental Shelf", February 2008, Available: http://www.oceanrenewable.com/wpcontent/uploads/2009/06/final_technical_report_iec_mms_200 8_0627.pdf, [last visited; 16th January 2015].

[20] Richard yemm, David pizer, Chris retzler AND Ross henderson, "The royal society publishing, Philosophical transaction A", Pelamis: experience from concept to connection. Available: http://rsta.royalsocietypublishing.org/content/370/1959/365, DOI: 10.1098/rsta.2011.0312 Published 19 December 2011.

[21] Chiang c. mei, "The royal society publishing, Philosophical transaction A", Pelamis: experience from concept to connection.Availabe: http://rsta.royalsocietypublishing.org, DOI: 10.1098/rsta.2011.0178 Published 19 December 2011.

[22] Ocean Waves, Available: http://hyperphysics.phyastr.gsu.edu/hbase/waves/watwav2.html, [last visited; 14th January 2015].

[23] Simulink home page, Available: http://www.mathworks.com/products/simulink/, [last visited; 14th January 2015]. 
[24] Simulink documentations, Available: http://www.mathworks.com/help/simulink/, [last visited; 14th January 2015].

[25] KhairulAnam, Husnain-Al-Bustam, "Cyber Journals, Multidisciplinary Journals in Science and Technology, Journal of Selected Areas in Renewable and Sustainable Energy (JRSE)", Power Crisis \& Its Solution through Renewable

\section{Biography}

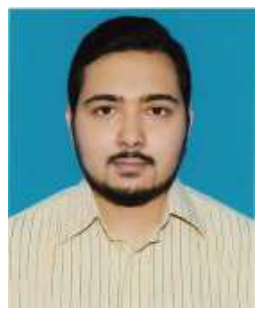

Miftah Al Karim received his M.Sc. from KTH Royal Institute of Technology, Sweden and bachelor degree from Islamic University of Technology (IUT), Bangladesh. Currently he is working as a faculty member at American University of Technology Bangladesh. Before that he worked as a research engineer at the department of Industrial Information and Control Systems at KTH and also as a product engineer at the department of Transmission Networks at the Huawei Technologies BD Ltd. His research interests are application of data mining in power system analysis, renewable energy technologies, electricity market analysis, power system optimization, intelligent energy management systems etc.

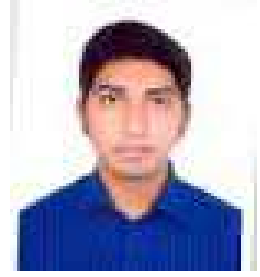

Mr. Md Hasib Noor currently has been working as a Faculty of Electrical and Electronic Engineering Department of American International University Bangladesh (AIUB). He has completed his graduation at Electrical and Electronic Engineering from Islamic University of Technology (IUT), Gazipur, Dhaka, Bangladesh. Then he has completed Masters at Telematics Engineering from UPC (Barcelona) and UC3M (Madrid), Spain with full Spanish Govt. funding. During that tenure, he was involved with different projects and research activities as well as with the ADSCOM research group of UC3M. He also completed MBA from IBA, Dhaka University of Bangladesh.

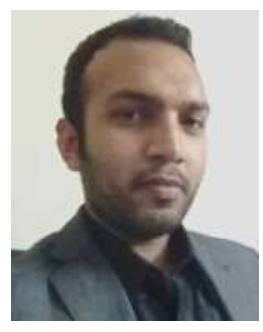

Mohammad Nasim was born on 27th July, 1987 in Dhaka, Bangladesh. He completed his bachelors in Mechanical Engineering from Islamic University of Technology (IUT) in 2009. After the completion of his bachelors in 2009. In 2011, he received Erasmus Mundus Scholarship in European Masters in Engineering Rheology (EURHEO). Most recently, he has been serving American International University Bangladesh (AIUB) as a lecturer in the department of Electrical and Electronics Engineering since January 2014. His research interests include renewable energy, materials for automotive, shear and extensional rheology, aeronautical and biomedical application, rheology for melts, solid state rheology, supramolecular assembled polymer.
Energy in Bangladesh, September Edition, 2011.

[26] RETscreen, Available: http://www.retscreen.net/ang/home.php, [last visited; 17th January 2015].

[27] Annual report 2012, Dhaka Power Distribution Company Limited (DPDC), Available: https://www.dpdc.org.bd/index.php/reports/annual-report, [last visited; 17th January 2015].

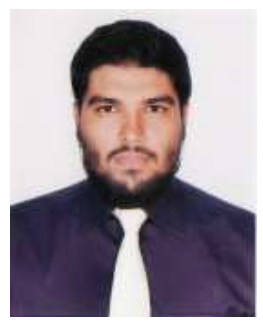

Saiful Islam Khan is currently working in American International UniversityBangladesh as a lecturer. He received his M.Sc. degree in Biomedical Engineering from Tampere University of Technology, Tampere, Finland with a major in Medical Instrumentation and minor in Biomaterials. He received his B.Sc. degree in Electrical and Electronic Engineering from Ahsanullah University of Science and Technology, Dhaka, Bangladesh. He worked as a research assistant in the Department of Biomedical Engineering, Tampere University of Technology, Tampere, Finland. Currently his research focus is in medical electronics, biosensor technology, and other interdisciplinary research work related to polymer, material and biomaterials etc. 